\title{
Influence of Relationship between Supply Chain Members on Innovation Performance
}

\author{
Qi Zhang \\ Economics School of Beijing Wuzi University, Beijing, China \\ Email: zhangqbjwz@163.com
}

Received June 2014

\begin{abstract}
In order to pursue development in fierce competition, enterprises have attached greater and greater importance to their innovation abilities. This paper analyzes the theory model about how the relationship between supply chain members can influence innovation performance. It is found that inter-firm trust and learning can help to promote relationship governance, and further enhance the innovation performance of the enterprises.
\end{abstract}

Keywords

Learning, Trust, Relationship Governance, Innovation Performance

\section{Introduction}

When enterprises try hard to maintain and improve competitiveness, organization innovation has got more and more attention. High uncertainty of the market and upgrading of technology turn out to present a severe test for enterprises to maintain competitive advantages. In this rapidly changing environment, it is more and more difficult for a single enterprise to get the latest knowledge and independently develop comprehensive technology. Innovative research has switched its attention from individual research to research of the whole internet [1]. People pay attention to the study of the organizational creativity and innovation performance of the industry cluster and the whole region [2]. How to make use of resources between enterprises to manage their relationship, thus promoting the innovation ability and competitiveness of the whole cluster? This article tries to integrate the micro enterprise characteristics and macro industry characteristics, and combine characteristics of the relationship between enterprises and external environment features of the cluster, in order to explore the process of localized innovation of enterprises in the cluster.

\section{Literature Review and Theoretical Assumptions}

In recent years, in spite the fact that research on relationship between enterprises has achieved fruitful results in relationship governance element, operation mechanism and relationship value, most of the research stays in research on the relationship governance between the alliance and network. It should be pointed out that, the establishment and maintenance of the cooperative/partner relationship needs a lot of resources, and it is not appropriate for all enterprises to establish long-term relationship. Enterprises should deploy limited resources to match 
the construction of the relationship [3]. It turns out that existing research ignores the study of characteristics of the relationship itself. In an industrial cluster, enterprises are embedded in a closer relational network. A potential assumption is that there exists high level of trust and knowledge sharing between enterprises, but due to fierce competitive conditions caused by close geographical position, geopolitical competition relations become more complex.

\subsection{Relationship Governance and Innovation Performance}

Relationship governance, brought up in the relational contract theory, is a kind of middle type of organization between market-oriented organization and hierarchical organization. The transaction cost theory emphasizes the role of hierarchical governance mechanism while the relational contract theory is concerned about the impact of social factors. From the perspective of relationship behavior process, relationship governance reflects the extent to which joint action could be organized, including joint planning and joint problem solving. Joint planning, as a predicting behavior, is a forecast for production status and distribution of rights and obligations in the relationship. Joint problem solving, being a reaction behavior, is to cooperatively solute new problems, situations and disputes caused by various reasons such as environment changes in the management process. Both sides choose to reduce opportunistic behaviors and take joint actions according to norms and their expectations of future long-term cooperation. Joint planning behaviors enable enterprises to establish good mutual expectations and make efforts to cooperate, speed up knowledge sharing and improve knowledge absorptive capacity, further to solve the problems arising in the course of cooperation and to strengthen innovation ability [4].It is obvious that improvement of relationship governance could strengthen the cognitive ability, information integration ability and the ability to remove bottlenecks, thus to promote an enterprise's innovation ability. Therefore, we assume that:

H1: Level of the relationship governance between enterprises is positively related to the improvement of innovation performance.

\subsection{Trust, Relationship Governance and Innovation Performance}

Trust reflects level of protocol fairness and commitment redemption. Trust is an important factor affecting long-term relationship orientation, and also is the essential condition of relationship governance. Firstly, trust can lower opportunistic behaviors before or after transaction, forming a lower level of hierarchical governance structure [5]. Secondly, considering from the perspective of social system theory, economic behaviors are embedded in the society, especially in the cluster where peer enterprises gathered in close geographical location, and business relationship and social relations between business owners are closely intertwined, forming trust based on township, geographical relationship, and blood relationship, Trusted trading companies will pay more efforts beyond the contract to overcome the difficulties [6]. So a high level of trust between enterprises improves relationship governance with norms as the core and reduces transaction costs. It is obvious that mutual trust between enterprises could help strengthen relationship governance level [7], take joint actions, as we mentioned before, further improve innovation performance. Therefore, we assume that:

H2: Trust between enterprises could improve relationship governance level.

H3: Mutual trust between enterprises improves innovation performance through relationship governance.

\subsection{Inter-Firm Learning, Relationship Governance and Innovation Performance}

Inter-firm learning refers to the process of trading parties passing and transferring knowledge [8]. In this process, shared information is usually special and implicit, and has scenario particularity and integrity. It is difficult to decode and express this kind of knowledge, making knowledge transferring challenging [9]. Obtaining valuable information of trading partners can reduce opportunistic behaviors, allowing both sides to better cope with the changes of business environment [10]. Especially, during enterprise management practice, due to supplier classification and certification management, reduction of the number of suppliers increased the dependence of both sides. In order to maintain synchronized development and respond to the new changes of the market, enterprises should keep common progress to make sure that knowledge provided could promote supervision and control enterprise production coordination, product development process and so on [11]. Besides, they can reflect market changes together. Especially, with the suppliers involved in the core business and participating in early research and development, inter-firm learning enables technical problems to be recognized and diagnosed in the 
early stage, providing a smoother communication platform for experts solving problems jointly. Furthermore, recognition of technology resources for both companies is more likely to happen, enabling technology development to be better planned and forecasted. So, knowledge exchange between trading partners has a positive impact on relationship governance between enterprises, provided with the above conclusion that good relationship governance positively leads to better innovation performance, it therefore promotes innovation performance accordingly. Therefore, we put forward the following hypotheses:

H4: Inter-firm learning has positive impacts on relationship governance.

H5: Inter-firm learning promotes enterprises' innovation performances through relationship governance.

\section{Research Method}

\subsection{Sample and Data Collection}

A total of 600 questionnaires were sent to enterprises in the Yangtze River Delta region, and finally 194 ones are valid. Manufacturing enterprises account for 50 percent. Manufacturing and distributing type of enterprises account for $32.5 \%$. Wholesaling and distributing type of enterprises account for $8.2 \%$. Retailing enterprises account for $3.6 \%$ and other types of enterprises account for $5.7 \%$.

\subsection{Measurement}

The measurement scale in the study of innovation performance is modified from Bell's (2005) study and includes three items. Relationship governance variables include three items [12], in order to reflect how the two sides of the particular partnership can reduce and manage opportunistic behaviors according to norms and expectations of long-term cooperation in the future [13]. In this study, industry, size, sales revenue, total assets are set as control variables. Each variable's reliability (Cronbach's $\alpha$ coefficient) and results of exploratory factor analysis are shown in Table 1 and Table 2.

Table 1. Items and results of exploratory factor analysis.

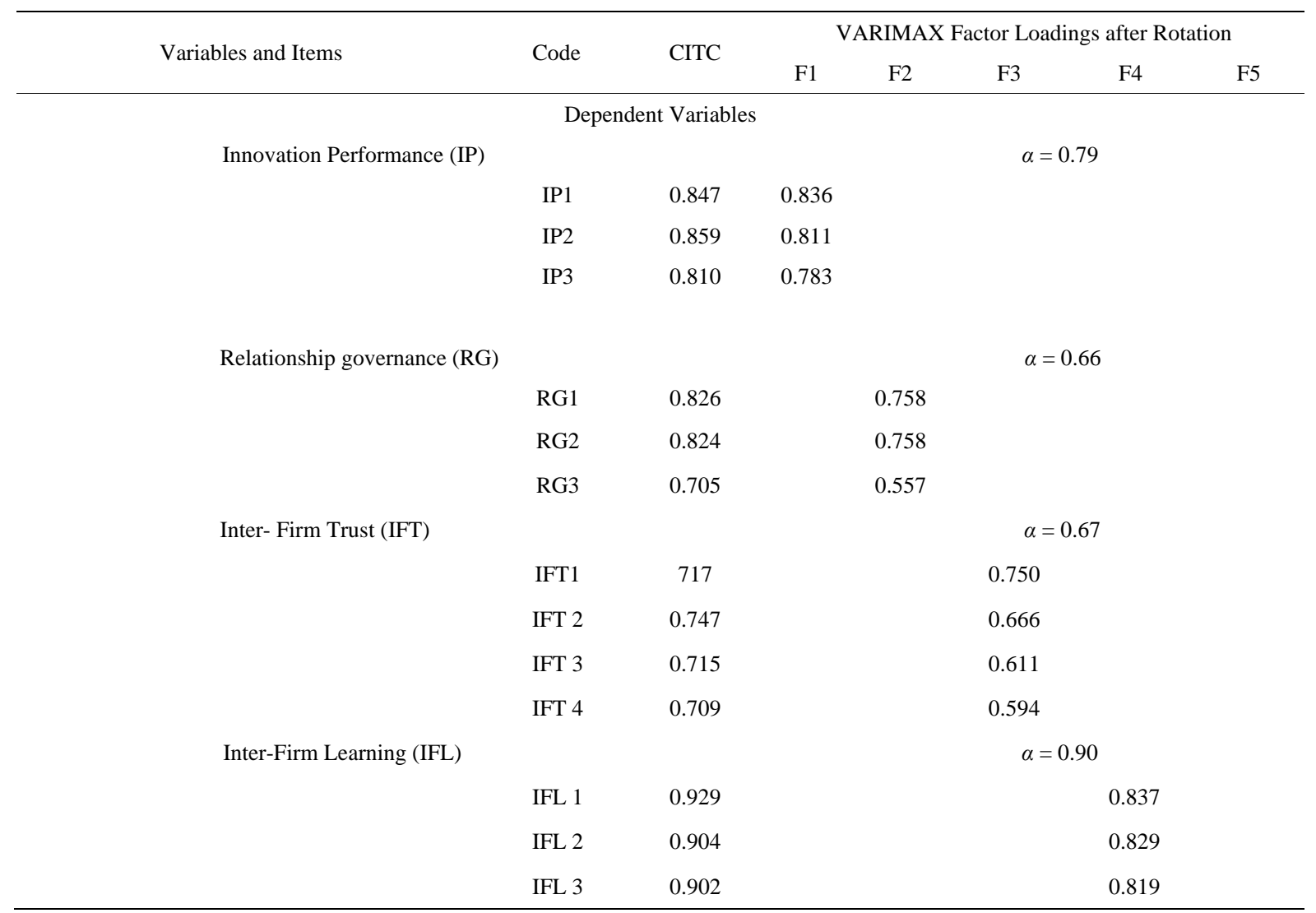


Table 2. Variables’ mean, standard deviation and correlation coefficient matrix.

\begin{tabular}{|c|c|c|c|c|}
\hline Variable & 1 & 2 & 3 & 4 \\
\hline 1. Trust & 1 & & & \\
\hline 2. Learning & $0.399^{* *}$ & 1 & & \\
\hline 3. Relationship governance & $0.353^{* *}$ & $0.535^{* *}$ & 1 & \\
\hline 4. Innovation Performance & $0.394^{* *}$ & $0.348^{* *}$ & $0.330^{* *}$ & 1 \\
\hline Mean & 30.771 & 30.377 & 30.904 & 4.242 \\
\hline Standard Deviation & 0.562 & 0.971 & 0.655 & 0.677 \\
\hline
\end{tabular}

a $\mathrm{N}=194$. b Numbers in diagonal are reliabilities. ${ }^{*} \mathrm{p}<0.05 ;{ }^{* *} \mathrm{p}<0.01$.

\section{Data Analysis Results (Table 3)}

As shown in Model 1, trust and learning has a significantly positive impact on innovation performance $(\beta$ Trust= 0.329 ; $\mathrm{p}<0.001 ; \beta$ Learning $=0.205 ; \mathrm{p}<0.01$ ). According to the test of null hypothesis 1 , relationship governance contributes to the improvement of innovation performance. The Step 3 in Model 1, for example, suggests that the former has a significantly positive influence on the latter. In the test of null hypothesis 2 and 4, relationship governance is taken as the dependent variable. As shown in the Step 2 of Model 2, trust and learning has a significantly positive impact on relationship governance $(\beta$ Trust $=0.168 ; \mathrm{p}<0.05 ; \beta$ Learning $=0.428 ; \mathrm{p}<$ 0.001). Adding the independent variables, trust and learning, increased R2, the degree of explained variation of the dependent variable, relationship governance, by 0.256 , which is significant at the significance level of $\mathrm{p}<$ $0.001(\triangle \mathrm{F}=7.979, \mathrm{p}<0.001)$.

In the test of null hypothesis 3 and 5 , as it is mentioned above, the trust and learning in the corporation has a significantly positive impact on innovation performance (See Step 2 of Model 1). Besides, the result of Model 1 reveals that relationship governance has a significantly positive influence on innovation performance. What is more, the effect is reduced when taking relationship governance into consideration $(\beta$ trust $=0.302 ; \mathrm{p}<0.001 ; \beta$ learning $=0.136 ; \mathrm{p}<0.05$ ). It shows that the relationship between independent variables and dependent variables is partially intermediated, which supports null hypothesis 3 and 5.

\section{Research Conclusions and Implications}

This thesis explores the localized innovation performance in a cluster considering the characteristics of industrial structure of the cluster. The research shows that the features of corporations' relationships affect the innovation performance via relationship governance, which is a partial intermediary variable. It means that the higher the level of trust and learning between companies, the better the level of relationship governance. The innovation performance, therefore, is improved. The study suggests that the external links improve the integration and optimization of information and professional knowledge at the corporation level. Besides, it motivates companies to innovate the reaction system to the changing of external needs through the relationship governance based on norms. This thesis also studies the scene effect of relationship governance. Besides illustrating the influence of relationship governance on innovation performance, the thesis introduces the characteristics of cluster's industrial environment, considers about the scene effect of cluster atmosphere and explores diverse effects of different relationship types on relationship governance. When the industries are highly similar, trust between corporations could increase the efficiency of relationship governance more. However, if the level of relationship governance is so high that it forms a high embedding degree of relations, the increase of innovation level will be restrained. The ideal embedding degree of relations, hence, is supposed to be moderate [14]. The research of [15] also proves that certain embedding degree of relations among the network promotes the performance, but it will reduce when the embedding degree exceeds the limitation.

Firstly, relationship governance could improve the efficiency of innovation performance. The supervisors will maintain and adjust the corporation relations better in order to dig the resources and capacities holding in the relations through joint action and integrated behaviors. The supervisors should encourage and cultivate the trust and learning among companies to promote the lever of relationship governance. Secondly, the supervisors need 
Table 3. Results of regression analysis.

\begin{tabular}{|c|c|c|c|}
\hline Variables & & Innovation Performance & \\
\hline & $\begin{array}{c}\text { Step } 1 \\
\text { Control }\end{array}$ & $\begin{array}{c}\text { Step } 2 \\
\text { Independent Variables (Main Effects) }\end{array}$ & $\begin{array}{c}\text { Step } 3 \\
\text { Intermediary Variables }\end{array}$ \\
\hline & Std. $\beta$ & Std. $\beta$ & Std. $\beta$ \\
\hline Industry & 0.048 & 0.028 & 0.035 \\
\hline Business Type & -0.120 & -0.129 & -0.129 \\
\hline Enterprises Scale & 0.099 & 0.120 & 0.124 \\
\hline Sales Revenue & -0.002 & -0.018 & -0.021 \\
\hline Total Assets & -0.102 & -0.121 & -0.128 \\
\hline Location & 0.062 & -0.019 & -0.032 \\
\hline Trust & & $0.329^{* * * *}$ & $0.302^{* * * *}$ \\
\hline Learning & & $0.205^{* *}$ & $0.136^{*}$ \\
\hline Relationship governance & & & $0.159^{* *}$ \\
\hline R2 & 0.030 & 0.228 & 0.245 \\
\hline$\triangle \mathrm{R} 2$ & - & $0.197^{* *}$ & $0.108^{* * * *}$ \\
\hline $\mathrm{F}$ & 0.909 & $6.407^{* * *}$ & $6.242^{* * *}$ \\
\hline
\end{tabular}

${ }^{\dagger} \mathrm{p}<0.10 ;{ }^{*} \mathrm{p}<0.05 ;{ }^{* *} \mathrm{p}<0.01 ;{ }^{* * *} \mathrm{p}<0.001$ (two-tails test).

to emphasize on the trust building among companies. Here needs to point out that when the level of relationship governance reaches a certain degree, the improvement of innovation performance will be blocked. The relations turn to have the lock-in effect and bring about the inertia of relations behaviors. Therefore, the supervisors need to build a complete system of performance evaluation and avoid the lock-in effect resulting from the exorbitant level of relationship governance. This thesis only discusses about the adjustment function of the industrial structure of a cluster. The further study could draw into the features of companies' internal resources and industrial environment features to enrich the theoretical model.

\section{Acknowledgements}

This thesis is supported by the 2013 Beijing Municipal Education Commission’s specific funding program: Research on Public Service Incubator of Small Enterprises of Creative Industries in Beijing, and 2011 Beijing Language and Culture University’s social-science project: Research on Internalization of RMB (Project No. 11GH05).

\section{References}

[1] Ketchen Jr., D.J. and Hult, G.T.M. (2007) Toward Greater Integration of Insights from Organization Theory and Supply Chain Management. Journal of Operations Management, 25, 455-458. http://dx.doi.org/10.1016/j.jom.2006.05.001

[2] Poter, M.E. (1990) The Competitive Advantage of Nations. Macmillan, London and Basingstoke

[3] Susan, L.G. and John, T.M. (2005) Exploring the Drivers of International Relationship Magnitude. Journal of Business Logistics, 26, 47-71. http://dx.doi.org/10.1002/j.2158-1592.2005.tb00205.X

[4] Dyer, J.H. and Singh, H. (1998) The Relational View: Cooperative Strategy and Sources of Inter-organizational Competitive Advantage. Academy of Management Review, 23, 660-679.

[5] Mcevily, B. and Marcus, A. (2005) Embedded Ties and the Acquisition of Competitive Capabilities. Strategic Management Journal, 26, 1033-1055. http://dx.doi.org/10.1002/smj.484

[6] Liu, K. and Wang, L. (2010) Research on the External Financing Efficiency of SMEs in Industrial Clusters: From the 
Perspective of Institutional Theory. Modern Economic Science, 2, 11-19.

[7] Song, H. and Wang, L. (2009) Does Learning Complement Trust? An Empirical Examination of Firm Innovativeness. Science of Science and Management, 4, 159-165.

[8] Lorenzoni, G. and Lipparini, A. (1999) The Leveraging of Inter-firm Relationships as a Distinctive Organizational Capability: A Longitudinal Study. Strategic Management Journal, 20, 317-338. http://dx.doi.org/10.1002/(SICI)1097-0266(199904)20:4<317::AID-SMJ28>3.0.CO;2-3

[9] Song, H. and Wang, L. (2012) The Impact of Relational Behavior between Enterprises on Innovation Flexibility. Science Research Management, 3, 1-10.

[10] Kane, G.C. and Alavi, M. (2007) Information Technology and Organizational Learning: An Investigation of Exploration and Exploitation Processes. Organization Science, 18, 796-812. http://dx.doi.org/10.1287/orsc.1070.0286

[11] Claro, P.D., Hagelaar, G. and Omta, O. (2003) The Determinants of Relational Governance and Performance: How to Manage Business Relationships. Industrial Marketing Management, 32, 703-716. http://dx.doi.org/10.1016/j.indmarman.2003.06.010

[12] Joshi, A.W. and Campell, A.J. (2003) Effect of Environmental Dynamism on Relational Governance in Manufacturer-Supplier Relationships: A Contingency Framework and an Empirical Test. Journal of the Academy of Marketing Science, 31, 176-188. http://dx.doi.org/10.1177/0092070302250901

[13] Lusch, R.F. and Brown, J.R. (1996) Interdependency, Contracting, and Relational Behavior in Marketing Channels. Journal of Marketing, 60, 19-38. http://dx.doi.org/10.2307/1251899

[14] Uzzi, B. (1997) Social Structure and Competition in Inter-firm Network. Administrative Science Quarterly, 42, 35-36. http://dx.doi.org/10.2307/2393808

[15] Håkansson, H. and Snebota, I. (1995) Developing Relationships in Business Networks. International Thomson Business Press, London, 65-100. 